\title{
Prevalence and predictors of resistant hypertension in a primary care setting: a cross-sectional study
}

Yook Chin Chia ${ }^{1,2^{*}}$ and Siew Mooi Ching ${ }^{3,4}$

\begin{abstract}
Background: Patients with resistant hypertension are subjected to a higher risk of getting stroke, myocardial infarction, congestive heart failure and renal failure. However, the exact prevalence of resistant hypertension in treated hypertensive patients in Malaysia is not known. This paper examines the prevalence and determinants of resistant hypertension in a sample of hypertensive patients.
\end{abstract}

Methods: We examined the control of blood pressure in a randomly selected sample of patients with hypertension in a primary care clinic. Demographic data, blood pressure and anti-hypertensive drug use were captured from patient records at the end of 2007. Resistant hypertension is defined as failure to achieve target blood pressure of $<140 / 90 \mathrm{mmHg}$ while on full doses of an appropriate three-drug regimen that includes a diuretic. Multivariate logistic regression was used for the analysis.

Results: A total of 1217 patients with hypertension were entered into the analysis. Mean age of the patients was $66.8 \pm 9.7$ years and $64.4 \%$ were female. More than half of the subjects (56.9\%) had diabetes mellitus. Median BP was 130/80 mmHg. Overall prevalence of resistant hypertension was $8.8 \%(N=107 / 1217)$. In multivariate logistic regression analysis, presence of chronic kidney disease is more likely to be associated with resistant hypertension (odds ratio [OR] 2.89, 95\% confidence interval [Cl] 1.56-5.35). On the other hand, increase per year of age is associated with lower odds of resistant hypertension in this population (OR 0.96, 95\% Cl 0.93-0.99).

Conclusions: Resistant hypertension is present in nearly one in ten hypertensive patients on treatment. Hypertensive patients who have underlying chronic kidney disease are associated with higher odds of having resistant hypertension. Hence, in managing patients with hypertension, primary care physicians should be more alert and identify patients with chronic kidney disease as such patients are more likely to develop resistant hypertension. By doing that, these patients can be treated more aggressively earlier in order to achieve blood pressure target and thus reduce cardiovascular events.

Keywords: Resistant, Hypertension, Primary care, Prevalence, Predictors, Chronic kidney disease Malaysia

\footnotetext{
* Correspondence: chiayc@um.edu.my

${ }^{1}$ Department of Primary Care Medicine, University of Malaya Primary Care

Research Group (UMPCRG), Faculty of Medicine, University of Malaya, 50603

Kuala Lumpur, Malaysia

${ }^{2}$ Curtin Health Innovation Research Institute, Faculty of Health Sciences,

Curtin University, GPO Box U1987, 6845 Perth, Western Australia, Australia

Full list of author information is available at the end of the article
} 


\section{Background}

Resistant hypertension is an important medical condition as uncontrolled blood pressure (BP) is associated with a fourfold risk of cardiovascular events compared with hypertensive patients achieving BP targets $[1,2]$. The definition of resistant hypertension varies. The Seventh Report of the Joint National Committee on Prevention, Detection, Evaluation, and Treatment of High BP defines resistant hypertension as failure to achieve BP to target despite adherence to appropriate treatment with full doses of at least 3 drug regimens including a diuretic [3]. On the other hand, the National Institute for Health and Care Excellence [4] and the European Society of Hypertension guidelines do not include the use of a diuretic in their definition [5].

Studies also show that resistant hypertension is associated with increasing age, female gender, black race, presence of diabetes, obesity, chronic kidney disease and left ventricular hypertrophy [6-14]. Early recognition of resistant hypertension followed by aggressive treatment is important to reduce both cardiovascular morbidity and mortality. However the exact prevalence of resistant hypertension is not precisely known due to its varied definition [3,15] and the setting of where the study was done. As such, based on several studies resistant hypertension has been reported to range from 5\% to $50 \%$ [16-19]. Furthermore most studies on resistant hypertension were done in secondary care and very few have been conducted in primary care.

Strokes are more common in Asia than in developed countries while the reverse is true for coronary artery disease [20]. Elevated BP is one of the most important risk factors for stroke $[21,22]$ and poorly controlled hypertension increases this risk $[3,23,24]$. Hypertension is of particular importance in South East Asia because while the prevalence of hypertension in Asian countries is nearly the same as that of most developed countries [25] , unfortunately many more patients in Asia with hypertension are not controlled to target $[26,27]$ compared to developed countries. For example, in developed countries the control rates of hypertension was around $52 \%$ [28] to $60 \%$ [29] but it is as low as $26 \%$ in Malaysia [30]. Resistant hypertension is one of the contributors of uncontrolled hypertension. Little is known about the prevalence of resistant hypertension in the South East Asian population. Hence we wanted to examine prevalence of resistant hypertension in treated hypertensive patients in a primary care setting in a South East Asian country to ascertain its contribution to uncontrolled hypertension.

\section{Methods}

\section{Setting}

We examined the control of blood pressure in a randomly selected sample of patients in an urban primary care clinic. Random numbers was generated by computer based on the patient registration number with the clinic. This selected sample consists of adult patients aged 30 years and older with hypertension who were treated and on long term follow-up in our primary care clinic. The study was conducted in an outpatient clinic of the University Malaya Medical Centre, a teaching hospital in Kuala Lumpur, the capital city of Malaysia. This clinic is run by 14 family medicine specialists, 30 vocational trainees in family medicine and other medical officers. This tertiary hospital including its primary care clinic serves a multi-ethnic population of 450,000 in the surrounding area.

People in the community can choose their own source of care. This teaching hospital functions on an open access basis to the community. A full range of services are offered at this clinic. Those who attend our clinic are mainly those requiring long term care of chronic conditions like hypertension, diabetes, dyslipidaemia in addition to the usual short term primary care illnesses.

Care is provided free for public sector service employees and their dependents while all others are required to pay an equivalent of US\$8.50 for both the consultation and a month's supply of medication. Our study population consists of three main ethnic groups, namely the Malays, Chinese and Indians [31].

Ethics approval for this study was obtained from the Ethics Committee of the University of Malaya Medical Centre.

\section{Inclusion criteria}

All patients with underlying hypertension were eligible for this study. Hypertension was defined as those who had a documented diagnosis of hypertension [i.e. BP $\geq$ $140 / 90 \mathrm{mmHg}]$ or those on anti-hypertensive agents.

\section{Data collection}

This sample was randomly selected using a computer generated number based on the patient's unique registration number with the clinic. All patient records were in paper form. We extracted the patients' information based on the last entry in 2007 from their records manually according to a predetermined proforma (clinical report form) which included the patient's socio demographic, blood pressure, weight, height, biochemical profile and use of antihypertensive agents. This was then entered into an electronic Excel spreadsheet and then converted to a SPSS format for analysis using SPSS version 21.

The data was captured by a trained and experienced abstractor and accuracy of data entry was checked by the investigators themselves.

Patients' blood pressure which was measured by the attending doctors as part of daily routine care were also captured from the medical records. Patients recruited into our study were those who had been diagnosed to have hypertension or were on antihypertensive medications. Diagnosis 
of hypertension in our clinics is made in accordance with standard recommendations i.e. based on at least 2 BP measurements at least 2 weeks apart [3]. Height and weight had been recorded using a stadiometer and digital weighing machine. We computed the body mass index (BMI) as weight in kilograms per square meter height $(\mathrm{kg} / \mathrm{m} 2)$.

We used the Cockcroft-Gault formula to calculate the estimated glomerular filtration rate (GFR) as a measure of renal function. The presence of chronic kidney disease (CKD) was defined as estimated GFR $<60 \mathrm{~mL} / \mathrm{min}$ per $1.73 \mathrm{~m}^{2}$.

Anti-hypertensive drug use was also captured from medical records and classified into the following classes: renin-angiotensin-system (RAS) inhibitors encompassing angiotensin-converting enzyme inhibitors (ACEI), angiotensin receptor blockers (ARB); beta-blockers, calcium-channel blocker (CCB), diuretics and alphablockers $\mathrm{N}$.

Resistant hypertension in this study is defined as office BP $\geq 140$ and/or $90 \mathrm{mmHg}$ despite the use of at least three antihypertensive drugs, one of which is a diuretic. Diabetes mellitus (DM) was based on the doctors' diagnosis or the use of hypoglycemic agents or both as stated in the medical records. Smokers were defined as current if they were still smoking; non smokers for those who never smoked or currently not smoking, regardless of when they had stopped smoking as indicated in the patient records.

\section{Statistical analysis}

All statistical analysis was done using the Statistical Package for Social Sciences (SPSS version 21). Continuous data are described as mean and standard deviation if the distribution is normal. When the data was a skewed distribution, median, minimum and maximum value were used to describe the data. Categorical data are reported as proportions (percentage). Chi-square test or Fisher exact tests were used for the categorical or dichotomous variables. Multivariate logistic regression analysis was used to look for the predictors of resistant hypertension. All variables with the p-value of less than 0.25 in the univariate analyses as well as clinically significant variables were entered into the multivariate logistic regression. The dependent variable was resistant hypertension (yes or no). The independent variables were age, gender, ethnicity, BMI, presence of diabetes, chronic kidney disease, dyslipidaemia and smoking status. All analyses were done with $95 \%$ confidence intervals $(\mathrm{CI})$, and the level of significance was set at $\mathrm{p}<0.05$.

\section{Results}

A total of 1222 hypertensive patients were eligible for this study. Out of this, 1217 (99.6\%) patients had complete drug therapy data and were entered into the analysis.
Table 1 shows the clinical characteristics of the studied population. Overall, the mean age of the patients was $66.8 \pm 9.7$ years; about two-thirds were female (66.4\%), and $59 \%$ were aged more than 65 years. The median BP was $130 / 80 \mathrm{mmHg}$. More than half of the populations (56.9\%) were diabetics with a mean HbA1c of $7.0 \pm 1.7 \%$. The mean eGFR of the studied population was $62.7 \pm$ $33.2 \mathrm{~mL} / \mathrm{min}$ per $1.73 \mathrm{~m}^{2}$ and a third (34.9\%) of the patients had underlying CKD.

The mean number of anti-hypertensive agents used was $2.0 \pm 1.0$. The control rate of those on 2 drugs was $52.3 \%$ while it was $48.0 \%$ for those on 3 drugs. Three fifths $(60.9 \%)$ of the diabetics and two fifths $(41.3 \%)$ of the patients with CKD were on 3 antihypertensive agents. Calcium-channel blockers were the most commonly prescribed drug (53.2\%) followed by angiotensin converting enzyme inhibitors or angiotensin receptor blockers (51.0\%), beta-blockers (44.5\%), diuretics (32.5\%) and alpha-blockers (3.5\%). For those patients who were on at least three drugs, $70.2 \%(n=181)$ were on diuretics and $29.8 \%(n=77)$ were not on diuretics. Among those patients who were on at least 3-antihypertensive agents including diuretics, $40.9 \%(n=74)$ achieved blood pressure target while $59.1 \%(\mathrm{n}=107)$ had resistant hypertension. On the other hand, of those on at least 3 antihypertensive drugs which did not include a diuretic 96.1\%, $(n=74)$ were controlled and $3.9 \%(n=3)$ were not controlled.

Overall prevalence of resistant hypertension was $8.8 \%$ $(\mathrm{N}=107)$ with $95 \%$ confidence interval (CI) 7.21-10.39.

\begin{tabular}{ll} 
Table $\mathbf{1}$ Clinical characteristics of the studied population \\
in UMMC (N= 1217) \\
\hline Characteristic of the subjects \\
\hline Mean Age \pm SD ,years & $66.8 \pm 9.7$ \\
Female, n, \% & $784(64.4)$ \\
Ethnicity, $n$, \% & \\
Malays & $312(25.6)$ \\
Chinese & $540(44.4)$ \\
Indians & $348(28.6)$ \\
Systolic blood pressure (IQR), mmHg & $130(90-220)$ \\
Diastolic blood pressure (IQR), mmHg & $80(50-110)$ \\
Resistant hypertension, $n$, \% & $107(8.8)$ \\
Presence of DM, n, \% & $693(56.9)$ \\
Missing value, n \% & $20(1.6 \%)$ \\
BMl (IQR), kg/m2 & $25.8(12.9-55.5)$ \\
Missing value, n, \% & $367(30.2)$ \\
presence of CKD, n, \% & $425(34.9)$ \\
Missing value, n, \% & $261(21.4)$ \\
\hline Smoker, n, \% & $86.1)$ \\
\hline
\end{tabular}

IQR: interquartile range. 
Table 2 Association between clinical variables among patients with and without resistant hypertension

\begin{tabular}{|c|c|c|c|}
\hline Variables & $\begin{array}{l}\text { No resistant HPT }(91.2 \%) \\
(\mathrm{n}=1110)\end{array}$ & $\begin{array}{l}\text { Resistant HPT }(8.8 \%) \\
(\mathrm{n}=107)\end{array}$ & $\mathbf{p}$ \\
\hline Age (years) & $66.9 \pm 9.5$ & $65.5 \pm 9.5$ & 0.15 \\
\hline Female, n, \% & $713(64.2)$ & $71(66.4)$ & 0.66 \\
\hline \multicolumn{4}{|l|}{ Ethnicity, n , \% } \\
\hline Malay & $281(25.4)$ & $31(29.0)$ & \multirow[t]{3}{*}{0.99} \\
\hline Chinese & $495(44.7)$ & $45(42.1)$ & \\
\hline Indians & $319(28.8)$ & $29(27.1)$ & \\
\hline $\mathrm{BMl}, \mathrm{kg} / \mathrm{m} 2$ & $26.3 \pm 4.8$ & $27.4 \pm 5.4$ & 0.08 \\
\hline Diabetes mellitus, n, \% & $672(61.3)$ & $67(62.6)$ & 0.79 \\
\hline Dyslipidaemia, n, \% & $734(66.1)$ & $76(71.0)$ & 0.34 \\
\hline Chronic kidney disease, n, \% & $377(43.5)$ & $48(53.3)$ & 0.08 \\
\hline Smoker, n, \% & $77(6.9)$ & $9(8.4)$ & 0.93 \\
\hline
\end{tabular}

HPT: hypertension, n: number, BMI: body mass index.

Table 2 compares the characteristics of those with and without resistant hypertension.

Table 3 shows the results of multivariate logistic regressions. After adjusting for all the variables in the model, age and presence of CKD were the main predictors. Presence of CKD among patients with hypertension were more likely to be associated with resistant hypertension compared to those without CKD (odds ratio [OR] 2.89, 95\% CI 1.565.35). Increasing age is less likely to be associated with resistant hypertension (OR 0.96, 95\% CI 0.93-0.99).

\section{Discussion}

The prevalence of resistant hypertension in this primary care setting is $8.8 \%$. This is lower than that reported in secondary care $[8,32,33]$ but is similar to another primary care study [18].

Our findings also show that hypertensive patients with CKD had 2.9 odds of having resistant hypertension compared to those without CKD. This is consistent with findings in other studies $[12,14]$. One possible reason is that in patients with CKD, there is increased sensitivity to salt resulting in sodium and fluid retention, thus making BP more difficult to control [34]. Another possible explanation is that in CKD, the RAS system is up regulated resulting in difficult to control BP [35].

Our study sample is made up of older patients as seen from the mean age of 66.9 years. That resistant hypertension is negatively associated with age could be due to the

Table 3 Predictors of resistant hypertension at UMMC $(\mathrm{N}=1217)$

\begin{tabular}{|c|c|c|c|c|}
\hline \multirow[t]{2}{*}{ Variables } & \multirow[t]{2}{*}{ Adjusted $\mathrm{OR}^{*}$} & \multicolumn{2}{|c|}{ 95\% C.I. } & \multirow[t]{2}{*}{$\mathrm{p}$ value } \\
\hline & & Lower & Upper & \\
\hline Chronic kidney disease & 2.89 & 1.56 & 5.35 & $0.001^{* *}$ \\
\hline Body mass index (per 1 kg/m2 increase) & 1.05 & 0.99 & 1.10 & 0.08 \\
\hline Age (per 1 year increase) & 0.96 & 0.93 & 0.99 & $0.007^{* *}$ \\
\hline Diabetes & 0.88 & 0.51 & 1.51 & 0.64 \\
\hline \multicolumn{5}{|l|}{ Ethnicity } \\
\hline Malays & 1.30 & 0.64 & 2.63 & 0.47 \\
\hline Chinese & 1.20 & 0.62 & 2.34 & 0.59 \\
\hline Indians & 1.00 & & & \\
\hline Smoking & 1.01 & 0.20 & 5.07 & 0.99 \\
\hline Dyslipidaemia & 1.33 & 0.73 & 2.42 & 0.36 \\
\hline \multicolumn{5}{|l|}{ Gender } \\
\hline Female & 1.57 & 0.90 & 2.74 & 0.11 \\
\hline Male & 1.00 & & & \\
\hline
\end{tabular}

*Adjusted odds ratio Cl: Confidence Interval. **p-value is $<0.05$. 
survival effect of fitter patients, whereby those with resistant hypertension had already succumbed to the complications of uncontrolled or resistant hypertension.

Previous studies have shown obesity to be associated with resistant hypertension [3], although we only found weak evidence $(\mathrm{p}=0.08)$ for such an association. A possible reason could be because of our small sample size of patients with resistant hypertension as the difference in body mass index between patient with and without hypertension resistant is not great $\left(27.4 \mathrm{~kg} / \mathrm{m}^{2}\right.$ versus $26.3 \mathrm{~kg} / \mathrm{m}^{2}$ ).

Furthermore studies have shown diabetes to be associated with resistant hypertension $[1,8,12]$ but we could not find any association in our study. This could be due to only a small difference in HbA1c between these two groups, where the mean HbA1c was $7.9 \pm 2.0 \%$ among patients with resistant hypertension versus HbA1c of $7.5 \pm 1.7 \%$ in patients without resistant hypertension, $\mathrm{p}=0.139)$.

Many studies have shown that most patients with hypertension need 2 or more drugs to achieve target $\mathrm{BP}$ [36-38]. Not surprisingly because the mean number of antihypertensive drugs used in our study was 2 . We also found poor control rates amongst those on only 2 drugs, even those on 3 drugs had lower than $50 \%$ control rate. When control is not to target particularly when patients are already on 3 drugs, the recommendation is that one of the drugs should be a diuretic. However we found that overall the use of diuretics was low. The definition of resistant includes use of a diuretic. Therefore, those patients on triple antihypertensive therapy but not including a diuretic, are not considered to have resistant hypertension in this study. This may therefore result in an underestimation of the true prevalence of resistant hypertension in our population.

In our study, it is possible that interaction between some of the factors of interest may explain the stronger associations evident in the multivariate compared with univariate regressions, particularly for CKD. However, this was not evident when interaction terms were included between CKD and BMI $(p=0.79)$ but significant interaction found between CKD and age $(\mathrm{p}<0.001)$.

\section{Strength and limitations}

Our present study has several strengths and some limitations. The strength of our study is that it is done in the primary care setting where the prevalence of resistant hypertension is different from that in secondary care. Secondly, our sample size is large enough to give us a better picture of the prevalence of resistant hypertension in primary care.

A limitation of our study is that adherence to medication was not available from the patient records. If adherence is taken into account, the "true" resistant hypertension may be lower as many studies have shown that "resistant hypertension" is frequently due to non-adherence. However doctors in routine daily clinical practice are not accurate in assessing adherence and even if adherence is assessed, this information is seldom recorded. Pill counting or use of electronic devices is indicated to confirm adherence, but this may not be practical in a real clinical setting [39-41].

\section{Conclusions}

The prevalence of resistant hypertension in this primary care population of patients with hypertension is relatively low. Nevertheless every effort is still needed to recognize it early. The presence of CKD is associated with higher odds of having resistant hypertension. On the other hand, increase in one year of age is associated with lower odds of having resistant hypertension in this population. These results indicate that clinicians should recognize resistant hypertension earlier, especially in those who have CKD so that early referral or intensifying therapy can be put in place.

\section{Abbreviations}

BP: Blood pressure; DM: Diabetes mellitus; BMI: Body mass index; $\mathrm{Kg} / \mathrm{m} 2$ : Kilograms per square meter; eGFR: Estimated glomerular filtration rate; N: Number; CKD: Chronic kidney disease; Cl: Confidence intervals; OR: Odds ratio; RAS: Renin-angiotensin-system.

\section{Competing interests}

The authors declare that they have no competing interests.

\section{Authors' contributions}

CYC contributed in the conceptualization of the paper, data entry and writing of the manuscript while CSM contributed in data analysis and writing of the manuscript. CYC is the corresponding author. Both the authors read and approved the final manuscript.

\section{Acknowledgements}

The authors would like to acknowledge University of Malaya for providing the research grant (UMRG 116/09HTM) and Department of Primary Care Medicine at the University of Malaya for providing support during data collection.

\section{Author details}

${ }^{1}$ Department of Primary Care Medicine, University of Malaya Primary Care Research Group (UMPCRG), Faculty of Medicine, University of Malaya, 50603 Kuala Lumpur, Malaysia. ${ }^{2}$ Curtin Health Innovation Research Institute, Faculty of Health Sciences, Curtin University, GPO Box U1987, 6845 Perth, Western Australia, Australia. ${ }^{3}$ Department of Family Medicine, Faculty of Medicine and Health Sciences, Universiti Putra Malaysia, 43400 Serdang, Malaysia. ${ }^{4}$ Department of Gerontology, Universiti Putra Malaysia, 43400 Serdang, Malaysia.

Received: 9 October 2013 Accepted: 30 June 2014

Published: 5 July 2014

\section{References}

1. Daugherty SL, Powers JD, Magid DJ, Tavel HM, Masoudi FA, Margolis KL, O'Connor PJ, Selby JV, Ho PM: Incidence and prognosis of resistant hypertension in hypertensive patients. Circulation 2012, 125(13):1635-1642.

2. Pierdomenico SD, Lapenna D, Bucci A, Di Tommaso R, Di Mascio R, Manente BM, Caldarella MP, Neri M, Cuccurullo F, Mezzetti A: Cardiovascular outcome in treated hypertensive patients with 
responder, masked, false resistant, and true resistant hypertension. Am J Hypertens 2005, 18(11):1422-1428.

3. Chobanian AV, Bakris GL, Black HR, Cushman WC, Green LA, Izzo JL, Jones DW, Materson BJ, Oparil S, Wright JT: Seventh report of the joint national committee on prevention, detection, evaluation, and treatment of high blood pressure. Hypertension 2003, 42(6):1206-1252.

4. National Institute for Health and Clinical Excellent: Hypertension: The Clinical Management of Primary Hypertension in Adults Clinical Guideline 127. http://www.nice.org.uk/guidance/CG127.

5. Cifkova R, Erdine S, Fagard R, Farsang C, Heagerty AM, Kiowski W, Kjeldsen S, Lüscher T, Mallion JM, Mancia G, Poulter N, Rahn KH, Rodicio JL, Ruilope $L M$, van Zwieten $P$, Waeber B, Williams B, Zanchetti A, ESH/ESC Hypertension Guidelines Committee: Practice guidelines for primary care physicians: 2003 ESH/ESC hypertension guidelines. J Hypertens 2003, 21:1779-1786.

6. Brown MJ, Castaigne A, De Leeuw PW, Mancia G, Palmer CR, Rosentha T, Ruilope LM: Influence of diabetes and type of hypertension on response to antihypertensive treatment. Hypertension 2000, 35(5):1038-1042.

7. Lloyd-Jones DM, Evans JC, Larson MG, O'Donnell CJ, Roccella EJ, Levy D: Differential control of systolic and diastolic blood pressure: factors associated with lack of blood pressure control in the community. Hypertension 2000, 36(4):594-599.

8. Cushman WC, Ford CE, Cutler JA, Margolis KL, Davis BR, Grimm RH, Black HR, Hamilton BP, Holland J, Nwachuku C, Papademetriou V, Probstfield J, Wright JT Jr, Alderman MH, Weiss RJ, Piller L, Bettencourt J, Walsh SM, ALLHAT Collaborative Research Group: Success and predictors of blood pressure control in diverse North American settings: the Antihypertensive and Lipid-Lowering and Treatment to Prevent Heart Attack Trial (ALLHAT). J Clin Hypertens 2002, 4:393-404

9. Wright JT Jr, Bakris G, Greene T, Agodoa LY, Appel LJ, Charleston J, Cheek DA, Douglas-Baltimore JG, Gassman J, Glassock R: Effect of blood pressure lowering and antihypertensive drug class on progression of hypertensive kidney disease. JAMA 2002, 288(19):2421-2431.

10. Bramlage P, Pittrow D, Wittchen HU, Kirch W, Boehler S, Lehnert H, Hoefler $M$, Unger T, Sharma AM: Hypertension in overweight and obese primary care patients is highly prevalent and poorly controlled. Am J Hypertens 2004, 17:904-910.

11. Aucott L, Poobalan A, Smith WCS, Avenell A, Jung R, Broom J: Effects of Weight Loss in Overweight/Obese Individuals and Long-Term Hypertension Outcomes A Systematic Review. Hypertension 2005, 45(6):1035-1041.

12. Calhoun DA, Jones D, Textor S, Goff DC, Murphy TP, Toto RD, White A, Cushman WC, White W, Sica D, Ferdinand K, Giles TD, Falkner B, Carey RM: Resistant Hypertension: Diagnosis, Evaluation, and Treatment: A Scientific Statement From the American Heart Association Professional Education Committee of the Council for High Blood Pressure Research. Hypertension 2008, 51(6):1403-1419.

13. Hyman DJ, Pavlik VN: Characteristics of patients with uncontrolled hypertension in the United States. N Engl J Med 2001, 345(7):479-486.

14. Sarafidis PA, Georgianos P, Bakris GL: Resistant hypertension-its identification and epidemiology. Nat Rev Nephrol 2013, 9(1):51-58.

15. Mancia G, De Backer G, Dominiczak A, Cifkova R, Fagard R, Germano G, Grassi G, Heagerty AM, Kjeldsen SE, Laurent S, Narkiewicz K, Ruilope L, Rynkiewicz A, Schmieder RE, Struijker Boudier HA, Zanchetti A, Vahanian A, Camm J, De Caterina R, Dean V, Dickstein K, Filippatos G, Funck-Brentano C, Hellemans I, Kristensen SD, McGregor K, Sechtem U, Silber S, Tendera M, Widimsky P et al: Guidelines for the Management of Arterial Hypertension: The Task Force for the Management of Arterial Hypertension of the European Society of Hypertension (ESH) and of the European Society of Cardiology (ESC). J Hypertens 2007, 25:1105-1187.

16. Papadopoulos DP, Papademetriou V: Resistant Hypertension: Diagnosis and Management. J Cardiovasc Pharmacol Ther 2006, 11(2):113-118.

17. Garg JP, Elliott WJ, Folker A, Izhar M, Black HR: Resistant hypertension revisited: a comparison of two university-based cohorts. Am J Hypertens 2005, 18(5 Pt 1):619-626.

18. Kaplan NM: Resistant hypertension. J Hypertens 2005, 23(8):1441-1444.

19. Viera AJ: Resistant Hypertension. J Am Board Fam Med 2012, 25(4):487-495.

20. Ueshima H, Sekikawa A, Miura K, Turin TC, Takashima N, Kita Y, Watanabe M, Kadota A, Okuda N, Kadowaki T, Nakamura Y, Okamura T: Cardiovascular Disease and Risk Factors in Asia: A Selected Review. Circulation 2008, 118(25):2702-2709.
21. O'Donnell MJ, Xavier D, Liu L, Zhang H, Chin SL, Rao-Melacini P, Rangarajan S, Islam S, Pais P, McQueen MJ: Risk factors for ischaemic and intracerebral haemorrhagic stroke in 22 countries (the INTERSTROKE study): a case-control study. Lancet 2010, 376(9735):112-123.

22. Chin CY, Pengal S: Cardiovascular disease risk in a semirural community in Malaysia. Asia Pac J Public Health 2009, 21(4):410-420.

23. Neal B, MacMahon S,NC: Effects of ACE inhibitors, calcium antagonists, and other blood-pressure-lowering drugs: results of prospectively designed overviews of randomised trials. Blood Pressure Lowering Treatment Trialists' Collaboration. Lancet 2000, 356:1955-1964.

24. European society if Hypertension-European Society of Cardiology Guidelines Committee: 2003 European Society of Hypertension European Society of Cardiology guidelines for the management of arterial hypertension. J Hypertens 2003, 21:1011-1053.

25. Whelton PK, He J, Muntner P: Prevalence, awareness, treatment and control of hypertension in North America, North Africa and Asia. J Hum Hypertens 2004, 18(8):545-551.

26. Ibrahim MM, Damasceno A: Hypertension in developing countries. Lancet 2012, 380(9841):611-619.

27. Chin CY, Keevil VL, Mooi CS: Antihypertensive Prescribing Pattern and Blood Pressure Control among hypertensive patients over a Ten Year period in a Primary Care Setting in Malaysia. Life Science Journal 2013, 10(1):2031-2035

28. Falaschetti E, Chaudhury M, Mindell J, Poulter N: Continued Improvement in Hypertension Management in England: Results From the Health Survey for England 2006. Hypertension 2009, 53(3):480-486.

29. Moser M, Franklin SS: Hypertension management: results of a new national survey for the hypertension education foundation: Harris interactive. J Clin Hypertens (Greenwich) 2007, 9(5):316-323.

30. Public Health Institute: Malaysia National Health And Morbidity Survey II Ministry of Health. ; 2006. vol. hypertension and hypercholesteronaemia.

31. Seto S: Left ventricular hypertrophy, ischemic heart disease and the incidence of cardiovascular events in Japanese high-risk hypertensive patients. Circ J 2009, 73(6):1014-1015.

32. Black HR, Elliott WJ, Grandits G, Grambsch P, Lucente T, White WB, Neaton JD, Grimm RH Jr, Hansson L, Lacourciere Y, Muller J, Sleight P, Weber MA, Williams G, Wittes J, Zanchetti A, Anders RJ, CONVINCE Research Group: Principal results of the Controlled Onset Verapamil Investigation of Cardiovascular End Points (CONVINCE) trial. JAMA 2003, 289(16):2073-2082.

33. Julius $S$, Kjeldsen SE, Brunner $H$, Hansson L, Platt F, Ekman S, Laragh JH, Mclnnes G, Schork AM, Smith B, Weber M, Zanchetti A: VALUE trial: Long-term blood pressure trends in 13,449 patients with hypertension and high cardiovascular risk. Am J Hypertens 2003, 16(7):544-548.

34. Weinberger MH: Salt Sensitivity of Blood Pressure in Humans. Hypertension 1996, 27(3):481-490.

35. Moser M, Cushman W, Handler J: Resistant or Difficult-to-Treat Hypertension. J Clin Hypertens 2006, 8(6):434-440

36. Dahlöf B, Sever PS, Poulter NR, Wedel H, Beevers DG, Caulfield M, Collins R, Kjeldsen SE, Kristinsson A, McInnes GT: Prevention of cardiovascular events with an antihypertensive regimen of amlodipine adding perindopril as required versus atenolol adding bendroflumethiazide as required, in the Anglo-Scandinavian Cardiac Outcomes Trial-Blood Pressure Lowering Arm (ASCOT-BPLA): a multicentre randomised controlled trial. Lancet 2005, 366(9489):895-906.

37. Cushman WC, Ford CE, Einhorn PT, Wright JT Jr, Preston RA, Davis BR, Basile JN, Whelton PK, Weiss RJ, Bastien A, Courtney DL, Hamilton BP, Kirchner K, Louis GT, Retta TM, Vidt DG, ALLHAT Collaborative Research Group: Blood Pressure Control by Drug Group in the Antihypertensive and LipidLowering Treatment to Prevent Heart Attack Trial (ALLHAT). J Clin Hypertens 2008, 10(10):751-760.

38. Black HR, Elliott WJ, Neaton JD, Grandits G, Grambsch P, Grimm RH, Hansson L, Lacouciere Y, Muller J, Sleight P: Baseline characteristics and early blood pressure control in the CONVINCE trial. Hypertension 2001, 37(1):12-18.

39. Mazzaglia G, Mantovani LG, Sturkenboom MC, Filippi A, Trifiro G, Cricelli C, Brignoli O, Caputi AP: Patterns of persistence with antihypertensive medications in newly diagnosed hypertensive patients in Italy: a retrospective cohort study in primary care. J Hypertens 2005, 23(11):2093-2100. 
40. Van Wijk BL, Klungel OH, Heerdink ER, De vBoer A: Rate and determinants of 10-year persistence with antihypertensive drugs. J Hypertens 2005, 23(11):2101-2107.

41. Vrijens B, Vincze G, Kristanto P, Urquhart J, Burnier M: Adherence to prescribed antihypertensive drug treatments: longitudinal study of electronically compiled dosing histories. BMJ 2008, 336(7653):1114-1117.

doi:10.1186/1471-2296-15-131

Cite this article as: Chia and Ching: Prevalence and predictors of resistant hypertension in a primary care setting: a cross-sectional study. BMC Family Practice 2014 15:131.

\section{Submit your next manuscript to BioMed Central} and take full advantage of:

- Convenient online submission

- Thorough peer review

- No space constraints or color figure charges

- Immediate publication on acceptance

- Inclusion in PubMed, CAS, Scopus and Google Scholar

- Research which is freely available for redistribution

Submit your manuscript at www.biomedcentral.com/submit
( Biomed Central 